
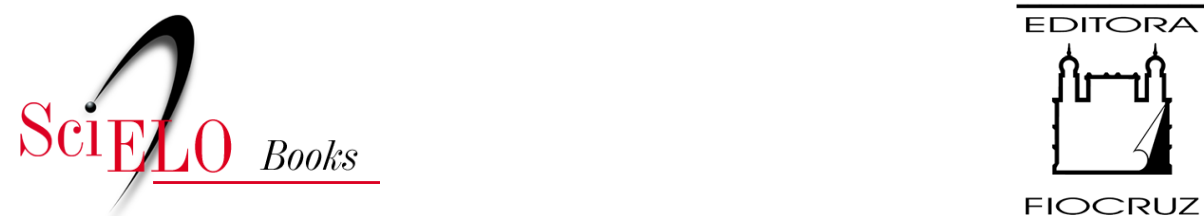

FIOCRUZ

\title{
Apresentação à segunda edição
}

\author{
Tania Maria Fernandes
}

\section{SciELO Books / SciELO Livros / SciELO Libros}

FERNANDES, T.M. Apresentação à segunda edição. In: Vacina Antivariólica: ciência, técnica e o poder dos homens, 1808-1920 [online]. 2nd ed. rev. Rio de Janeiro: Editora FIOCRUZ, 2010, pp. 1127. ISBN: 978-65-5708-095-5. https://doi.org/10.7476/9786557080955.0001.

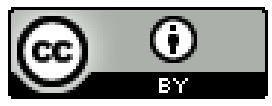

All the contents of this work, except where otherwise noted, is licensed under a Creative Commons Attribution 4.0 International license.

Todo o conteúdo deste trabalho, exceto quando houver ressalva, é publicado sob a licença Creative Commons Atribição 4.0.

Todo el contenido de esta obra, excepto donde se indique lo contrario, está bajo licencia de la licencia Creative Commons Reconocimento 4.0. 


\section{Apresentação à Segunda Edição}

A varíola e a vacina antivariólica constituem temas importantes e estão presentes em vários debates que apontam para análises histórias, tanto acerca da saúde pública nacional e mundial, como em torno de alguns objetos de investigação de âmbito político, social e cultural, em diversos contextos. As últimas duas décadas nos apresentam um significativo quadro de análises, tanto no que diz respeito a questões que se concentram no século XIX e nos primeiros anos do século XX, quanto a outros estudos que assumem amplo temário, inclusive a perspectiva de erradicação da varíola e de outras doenças, ao longo do século XX e primeira década do XXI.

Entre as reflexões que envolvem ou tangenciam o controle da varíola, no Brasil, acerca do período que se estende até o início do século XX, destacamos aquelas elaboradas por alguns estudiosos. A publicação de Sidney Chalhoub (1996), Cidade Febril: cortiços e epidemias na Corte imperial, além de estabelecer importante discussão acerca da prática médica no século XIX, aponta questões singulares sobre a utilização e difusão da variolização. Jayme Benchimol (1990, 1999) trouxe relevante contribuição com reflexões em torno da medicina pasteuriana e da trajetória do Instituto Oswaldo Cruz, que apresenta sua origem vinculada à uma parte da história da vacina antivariólica. Luiz Antonio Teixeira (2000) 
dedicou-se à análise da institucionalização de saberes médicos e as controvérsias geradas entre eles, discutindo o diagnóstico da varíola e sua similaridade com o alastrim. Sandra Caponi (2002a, 2002b) dedica-se ao estudo do pasteurianismo e sua relação com o contagionismo, verificando a postura das diferentes correntes que se mantiveram presentes entre o século XIX e XX, ressaltando a varíola como importante exemplo da definição de posições antagônicas ou não.

O episódio conhecido como A Revolta da Vacina, ocorrido no Rio de Janeiro no início do século XX, propiciou uma série de reflexões que colocam a varíola e as propostas de organização dos serviços sanitários no centro de um debate mais amplo, nas esferas social, política e econômica. Sidney Chalhoub (1996), José Murilo de Carvalho (1987), Jeffey Needell (1987), Nicolau Sevcenko (1984), Cláudio Bertolli Filho e José Carlos Sebe Bom Meihy (1999), Miriam Bahia Lopes (1996), Ângela Pôrto (1985) e Jaime Benchimol (1990, 2003), analisam sob vários aspectos esse momento da história da cidade e as causas que propiciaram o estopim dessa revolta popular, tanto pela ótica do estabelecimento do controle social, via medidas sanitárias coercitivas, quanto por um foco de cunho político, econômico e social.

Outras importantes investigações tratam da varíola e da vacina a partir de estudos circunscritos a regiões específicas em vários lugares do mundo, como, por exemplo, o trabalho desenvolvido por Maria Silvia Di Liscia (2002) que trata da difusão da varíola e da vacina como estratégia de extermínio e controle étnico da população indígena na Argentina. O estudo de Monica Saavedra (2004), pesquisadora da Universidade de Lisboa, nesta mesma perspectiva, analisa a vinculação entre as práticas de vacinação antivariólica, as relações de poder e as questões científicas e técnicas geradas localmente, em estudo sobre a ex-colônia portuguesa de Goa, na Índia. Marcos Cueto (1997, 2004), pesquisador peruano, desenvolveu importantes estudos no campo da história das doenças, buscando, inclusive, apontar os conflitos gerados e os apoios a médicos recebidos por parte da população em função de orientações sanitárias e medidas governamentais de controle de doenças, como o tifo e a varíola, no Peru.

No que diz respeito às análises, de cunho histórico, referentes à saúde pública, no período entre a década de 1920 e 1940, detecta-se pouca alusão à vacina antivariólica e à varíola. Os acontecimentos do fim dos anos 50 até os anos 70 do século XX, no entanto, diante das propostas de âmbito internacional de erradicação da varíola, vêm suscitando a 
elaboração de vários estudos. Estes trazem contribuições significativas, com análises acerca das políticas e das experiências nacionais e internacionais, assim como das ações de vigilância epidemiológica, vacinação e educação sanitária. Citamos, neste sentido, alguns estudos voltados para experiências locais, na Índia e na África, como os elaborados por Sanjoy Bhattacharya (2006, 2008), Willian Schneider (2009), Donald Hopkins (1976, 1983) e Paul Greenough (1995). Após a erradicação mundial, Frank Fenner et al. (1988) elaboraram, no âmbito da Organização Mundial da Saúde (OMS), um amplo estudo abordando as campanhas de erradicação desenvolvidas nos diversos países, além das características etiológicas da doença, configurando-se como importante retrato institucional do processo.

No Brasil, na primeira década do século XXI, desenvolveram-se pesquisas sobre a experiência brasileira e as ações institucionais para a erradicação da varíola, como as elaboradas por Tania Maria Fernandes $(2005,2006)$ e as produzidas pela mesma autora em parceria com Daiana Crús Chagas e Érica Mello de Souza, onde os projetos educativos configuraram questões relevantes (2007, 2010a, 2010b). Ainda sobre o processo de erradicação da varíola destacam-se os estudos de Daiana Crús Chagas (2008), Arlene Gazêta (2001, 2006) e Arlene Gazêta et al. (2005). Uma análise acerca das imagens que envolvem vacinas foi idealizada por Ângela Pôrto e Carlos Fidelis da Ponte (2005) e também merece destaque. Ainda nesse viés analítico, porém apontando para a internacionalização da saúde e a implementação de programas de erradicação da malária e da varíola, no Brasil, destacam-se os estudos elaborados por Gilberto Hochman (2007, 2008a, 2008b, 2009) Gilberto Hochman e Diego Armus (2004) e Gilberto Hochman, Marta Arretche e Eduardo Marques (2007), que refletem, inclusive, a perspectiva de ampliação do diálogo e o estabelecimento de parcerias internacionais expressas em publicações, como a concretizada com Steven Palmer (2010) e Anne-Emanuelle Birn (2006).

Profundas contribuições são detectadas, ainda, a partir das investigações de Anne Marie Moulin (1991, 1996, 1999, 2003), em que é ressaltada a complexidade do fenômeno vacinal, numa aproximação entre as ciências sociais e biológicas, na perspectiva da construção de uma antropologia das vacinas que se debruce na análise das resistências e reticências das populações com relação às vacinas. Pierre Darmon (1984, 1986, 1991, 1999) elabora, também, reflexões relevantes acerca do conhecimento sobre o processo imunitário, com ênfase na varíola, na variolização e na vacinação. 
Estudos no campo da história das doenças contribuíram, igualmente, para importantes orientações, ao apontarem as doenças como fenômenos sociais, o que possibilita sua compreensão de forma dinâmica e múltipla para além da dimensão biológica. Diversos autores aprofundaram esse aspecto por meio de variadas perspectivas, em torno de diversos objetos analíticos e várias doenças. Destacamos, neste sentido, as publicações de Charles Rosenberg (1995) - que já constitui obra de referência para a discussão acerca do tema -, Diego Armus (1987, 2000, 2004) - que aprofundou estudos acerca das doenças e da medicina na América Latina, em especial na Argentina - e Claudine Herzlich (1991), que em parceria com Janine Pierret (1984) elaborou importante reflexão sobre a representação social da doença diante de características singulares, dos contextos políticos e culturais, incluindo a morte como um dos fatores de diferenciação. Alfred Crosby $(1973,1993,1999)$ apresenta argumentos relevantes para os estudos demográficos e epidemiológicos observando a difusão das doenças como delimitador de alguns processos de ocupação territorial, com destaque para as epidemias.

No Brasil, tal campo se consolidou no meio acadêmico com evidência para alguns estudiosos como Dilene Raimundo do Nascimento (2004, 2005), que em parceria com Anny Jackeline T. da Silveira (2004) e com Diana Maul de Carvalho e Rita de Cássia Marques (2006) promoveu debates e elaborou reflexões em torno de algumas doenças - tuberculose, Aids, poliomielite e hanseníase. Cláudio Bertolli Filho (1992, 2000a, 2000b, 2001, 2008) desenvolveu estudos sobre a representação de doenças e o processo de constituição de estigmas sociais como no caso do câncer e da tuberculose, e Jaime Benchimol (2001), em outro viés, elaborou um importante estudo acerca da febre amarela, onde discute técnicas de laboratório, articulações internacionais e relaciona as pesquisas e a produção da vacina antivariólica à antiamarílica.

Esse conjunto de reflexões contribuiu significativamente para nossas investigações acerca da varíola e da vacina, tanto as que se concentraram no século XIX e primeiros anos do século XX (Fernandes, 1989, 1999, 2003, 2004a) - como no caso desta publicação que ora apresentamos em segunda edição -, quanto as que assumem, como tema central, o controle e a erradicação da doença a partir de meados do século XX (Fernandes, 2004b, 2005, 2006; Fernandes \& Chagas, 2007; Fernandes, Chagas \& Souza, 2010a, 2010b). Buscamos, mediante tais pesquisas, e das publicações que por conseguinte originaram, analisar o processo de 
institucionalização da vacina antivariólica no Brasil e os principais personagens envolvidos, desde o início do século XIX até a erradicação da doença no país, na década de 1970. Além disso, estabelecemos reflexões sobre alguns debates que envolveram tanto a Academia de Medicina, como as principais faculdades de medicina. As discussões veiculadas nos periódicos médicos e jornais leigos também se constituíram importantes fontes para a análise do papel da doença e da vacinação em seus aspectos políticos e sociais.

Os temas centrais da publicação - Vacina Antivariólica: ciência, técnica e o poder dos homens (1808-1920) - agora reeditada, se configuram em torno do processo brasileiro de institucionalização das duas principais vacinas utilizadas como preventivas contra a varíola - a vacina de Jenner e a vacina animal. Assumimos como marco inicial a introdução da vacina de Jenner, na primeira década do século XIX, e finalizamos com a incorporação da produção da vacina de origem animal ao Instituto Oswaldo Cruz, em 1920. Não ignoramos, no entanto, a importância histórica da difusão da técnica de variolização utilizada anteriormente e, ainda durante algum tempo, após a descoberta de Jenner, durante o século XIX, mas não a assumiremos como objeto de análise.

O título Vacina Antivariólica: ciência, técnica e o poder dos homens (1808-1920) busca refletir o processo analítico que traçamos a partir da relação entre alguns aspectos (conhecimento científico e técnicas de produção do imunoterápico) e o poder exercido por políticos, médicos e cientistas sobre a doença e o ser humano, sob inspiração do compositor e cantor brasileiro Caetano Veloso, ao apregoar ao homem a capacidade de "apodrecer" seus próprios poderes.

Ao apresentar a segunda edição deste livro, apontamos algumas questões que delimitaram as investigações que procedemos sobre o tema, após este estudo específico, que completou 11 anos, na perspectiva de mapear nossas investigações, ampliar o debate acerca da vacinação e atualizar a temática diante da erradicação da doença conquistada na década de 1970, sobre a qual nos debruçamos recentemente.

\section{A Varíla e a Vacina: a construção de uma história}

Com alto grau de letalidade, a varíola dizimou populações, ao longo de séculos, nas formas endêmica e epidêmica. O quadro clínico era 
gravíssimo e considerado 'asqueroso', com pústulas infeccionadas que, naqueles que escapavam com vida, se transformavam em cicatrizes típicas e profundas, localizadas, principalmente, no rosto. Várias foram as tentativas de controlar sua expansão, tomando como base a percepção de que existia uma forma branda da doença e de que algumas pessoas se mostravam resistentes a ela, mesmo diante de contato próximo com enfermos. A constatação da transmissibilidade e da imunidade, próprias da doença, impulsionou a disseminação de técnicas que buscavam evitar sua forma mais grave a partir da implantação, no homem sadio, do vírus variólico contido na secreção retirada das pústulas de pessoas doentes (Benchimol, 2001, Chalhoub, 1996; Darmon, 1986; Fernandes, 1999, 2003, 2004; Moulin, 1991, 1996; Teixeira, 2000).

Diferentes técnicas foram empregadas com essa perspectiva, desde práticas empíricas de inoculação da própria doença (conhecidas como variolização, inoculação ou transplantação), até a aplicação de um vírus semelhante, como foi o caso da vacinação onde se inoculava o vírus de uma doença típica de bovinos, o cow-pox (Fernandes, 1999, 2003).

A variolização, inoculação, transplantação e vacinação se constituíam na implantação de agentes virais semelhantes (vírus da varíola e do cow-pox), que produziam pústulas locais similares e que podiam induzir a fabricação de anticorpos capazes de imunizar o organismo contra as duas doenças. A diferença entre elas, além da identidade do vírus, se constituía no fato de as três primeiras pautarem-se na aplicação do vírus da doença humana in natura (sem atenuação de sua virulência), passível de provocar a doença em qualquer de suas formas (branda e letal) e de viabilizar tanto a imunidade individual quanto a disseminação da doença. A vacina antivariólica, ao contrário, tinha como base a aplicação do vírus do cow-pox, que produzia imunidade tanto para a doença do bovino quanto para a varíola. Sua criação é atribuída à Jenner ${ }^{1}$ e se constituía da aplicação subseqüente, de pessoa a pessoa, do germe multiplicado a partir de tais aplicações (Fernandes, 1999, 2003).

A vacina se difundiu por quase todos os países do mundo mais de um século antes da incorporação do método experimental à medicina, ao término do século XVIII, da elucidação do processo imunológico e da fabricação de vacinas em escala industrial, que só ocorreram no século XX.

A técnica original de produção da vacina de Jenner foi alterada a partir de testes empíricos, diante da constatação da inocuidade da vacina e da conseqüente perda da defesa contra a doença nos indivíduos vacinados, 
detectada na primeira década do século XIX, com a disseminação da vacina no mundo. Uma das medidas adotadas foi a implantação de uma nova vacina extraída diretamente do corpo de bovinos, inoculado com o vírus do cow-pox, e outra foi a revacinação. As duas medidas - vacinação animal e revacinação - geraram amplas discussões e provocaram uma série de reações contrárias, mas que, no entanto, não impediram a plena difusão da vacina (Fernandes, 1999, 2003, 2004).

Além das mudanças bastante significativas na produção da vacina de origem bovina, observa-se também, a partir do fim do século XIX, a realização de testes e pesquisas que buscavam a purificação e produção do líquido vacínico em outros organismos vivos utilizados em laboratório. A aplicação de glicerina como purificante e conservante da vacina foi adotada de forma generalizada, desde 1866, como fruto dessa perspectiva, contribuindo para a minimização dos efeitos colaterais conseqüentes da vacinação, a partir do uso no Instituto Vacínico de Berlim (Fernandes, 2003). A introdução do laboratório experimental, da microbiologia e da imunologia possibilitaram o isolamento do vírus além do cultivo em tecido celular (em ovo embrionado e em células de coelho), o que ao longo do século XX foi adotado sem, no entanto, substituir completamente a produção da vacina em vitelos (Fernandes, 1999, 2005).

Cercadas de várias questões, a varíola e a vacina sugerem diversos temas para análise, como os paradigmas científicos, as políticas de saúde, as discussões políticas e científicas, as reações populares que esse tema envolve, além da vulnerabilidade humana e política acarretada pela falta de proteção imunológica com a eliminação do vírus circulante, conseqüência da erradicação da doença.

\section{A Varíola e Vacina no Brasil: enfrentamentos e disputas no século XIX}

Observam-se, no decorrer do século XIX, no Brasil, intenso debate e negociações no âmbito das ainda poucas instituições acadêmicas e dos fóruns políticos, além dos espaços de divulgação acadêmica e leiga quanto à utilização de várias práticas concomitantes, tanto de vacinação humanizada quanto da variolização, inoculação ou transplantação (Fernandes, 1999, 2003, 2004). 
A Academia de Medicina brasileira (originalmente, Sociedade de Medicina do Rio de Janeiro) constituía um desses fóruns, com as reuniões periódicas e a publicação dos debates que fomentava. Prestava, também, assessoria ao governo no que dizia respeito a questões de saúde, por meio das comissões temáticas que organizava, constituindo, inclusive, um grupo para estudo específico sobre a vacina antivariólica. Os debates acerca das diferentes concepções de doença e dos possíveis agentes, miasmático e microbiano, presentes no âmbito da academia, são extremamente férteis para os estudos a respeito da legitimação da medicina no país e a adoção de medidas de cura e prevenção específicas no século XIX. Com relação à varíola e à imunização importa ressaltar que, nessa discussão, ambas eram associadas à transmissão direta, tanto do vírus variólico, como do vacínico, não cabendo explicações para a transmissibilidade da doença que se pautassem em estados de putrefação ou eflúvios miasmáticos, o que colocava a doença no debate em torno do contagionismo (Fernandes, 2004).

As revistas médicas se configuravam como espaços para a promoção de debates relacionados à medicina no país, mediante a publicação de textos nacionais e estrangeiros. Simbolizavam, sobretudo, o movimento de organização e busca de legitimidade do corpo médico brasileiro a partir da divulgação dos conflitos e dos consensos que orientavam as sociedades médicas de vários países e pautavam parte das ações médicas no Brasil. A Gazeta Médica da Bahia, a Gazeta Médica do Rio de Janeiro e a Revista Médica Fluminense revelam-se como as publicações mais significativas de divulgação de textos sobre a varíola e a imunização. A Academia de Medicina configurava-se, igualmente, como lócus de conformação do pensamento médico no país, por meio de suas reuniões e da publicação dos Annaes. No fim do século XIX observa-se marcadamente a utilização desses vários fóruns de debates para a difusão da medicina experimental, tanto no que diz respeito ao seu aspecto técnico-científico, como no que tange às questões sociopolíticas e culturais (Fernandes, 2003, 2004). ${ }^{2}$

Vários estudos publicados nesses periódicos dedicavam-se a levantamentos estatísticos contabilizando resultados sobre inoculações do vírus variólico e vacinações, na perspectiva de balizarem as opiniões dos médicos acerca da revacinação, da vacinação durante períodos de epidemia, da opção entre vacina humanizada e animal, ou mesmo sobre a inoculação do vírus variólico e a obrigatoriedade da vacinação. Também eram comuns os artigos que retratavam uma preocupação com a transmissão de 
outras doenças por intermédio da vacinação humanizada, como a sífilis e a tuberculose (Fernandes, 2003, 2004).

O diagnóstico da varíola constituía-se também um ponto polêmico, pois em períodos não epidêmicos a doença era facilmente confundida com outras enfermidades eruptivas, como o alastrim (Fernandes, 2004; Teixeira, 2000). A institucionalização, assim como a preocupação com os profissionais que praticavam a vacinação era um tópico menos constante, mas presente nesses debates (Fernandes, 2003, 2004).

No fim do século XIX e início do século XX, com a consolidação das experiências laboratoriais, tomam vulto, nas publicações e nos debates, outros temas e métodos que se voltavam para a identificação do vírus responsável pela doença, para o desenvolvimento de novas técnicas de produção e aplicação da vacina e para a compreensão do processo que originava a imunidade.

\section{Instituições: produção, difusão e aplicação da vacina}

A difusão institucionalizada da vacina, no Brasil, teve início em 1811, com a criação da Junta Vacínica da Corte, como uma das primeiras medidas assumidas por D. João VI ao chegar ao Brasil. A vacinação obrigatória, no entanto, só foi instituída em 1832, em grupos específicos, sendo ampliada em 1846 pelo decreto de criação do Instituto Vacínico do Império, que sofreu mudanças ao longo do século, até sua extinção em 1886, quando a vacinação foi incluída nas responsabilidades da Inspetoria Geral de Higiene. Na realidade, a difusão da vacina e de outros processos de imunização, ao longo do século XIX, contavam, de forma expressiva, com a iniciativa de particulares, profissionais médicos ou não (Fernandes, 1999, 2003, 2004).

A introdução da vacina animal, indicada como mais eficaz e adotada nos países europeus, desde meados do século, somente chegou ao Brasil em 1887, por iniciativa do barão de Pedro Affonso, ${ }^{3}$ o que se configurou como ponto central do estudo que originou a publicação que ora apresentamos em sua segunda edição.

A trajetória do Instituto Vacínico Municipal (do Rio de Janeiro), criado em 1894, revela aspectos importantes da configuração da saúde pública no Brasil, pela singularidade de sua história e pelas polêmicas 
travadas em torno de sua manutenção como uma instituição privada, porém subvencionada pelo Estado. A criação desse instituto pelo médico barão de Pedro Affonso, ao final do Brasil Império, representou uma ‘solução' governamental para o problema da institucionalização da vacina antivariólica no Brasil ao introduzir a vacina animal, estabelecendo uma importante mudança institucional e científica.

Como ‘solução’ governamental, o Instituto Vacínico Municipal rompeu a inércia do Estado diante das questões relativas à vacinação que as instituições criadas ao longo do governo imperial não tinham alterado. O Instituto criou um novo debate, decorrente da ausência de consenso da classe médica, com a introdução da vacina de origem animal no país em substituição à vacina humanizada.

Paralelamente à criação do Instituto Vacínico Municipal, o barão de Pedro Affonso criou e dirigiu durante dois anos - 1900 a 1902 - o Instituto Soroterápico Federal (ISF), ${ }^{4}$ inicialmente destinado à fabricação de soro antipestoso. O ISF, após longo processo de negociação entre o barão, a prefeitura da cidade e a União, foi configurado, diferentemente do Instituto Vacínico Municipal, como um órgão da administração federal e não como uma instituição com características filantrópicas (Fernandes, 1989). Os laboratórios que compunham o ISF, também conhecido como Instituto de Manguinhos, estavam instalados em prédios de construção bastante simples, distantes da suntuosidade que exibe desde o fim da primeira década do século XX.

Para trabalhar na instituição, ainda nos laboratórios originais, Pedro Affonso convidou Oswaldo Cruz, Ismael da Rocha, Henrique Vasconcelos e Ezequiel Dias, que se transformaram em expoentes da pesquisa científica no Brasil (Fernandes, 1989).

As concepções divergentes representadas por Oswaldo Cruz e Pedro Affonso, contrapondo, principalmente, moderno/conservador, dispendioso/econômico, centralização/descentralização dos serviços, geraram profundos conflitos públicos entre os dois personagens, o que acarretou o pedido de afastamento de Pedro Affonso da direção do ISF, em dezembro de 2002, formulada por ele. Oswaldo Cruz, no comando da Diretoria Geral de Saúde Pública e do ISF, e com forte sustentação política na república de Rodrigues Alves, viu seu projeto de centralização dos serviços de saúde legitimado pela proposta de transformação e modernização do Distrito Federal. Apesar do poder e do apoio angariado por Oswaldo Cruz, o Instituto Vacínico manteve-se com a mesma 
estrutura, como uma exceção aos projetos de centralização dos serviços de saúde. No decorrer do período de sua sobrevivência, a instituição vacínica atuou subvencionada pelo Estado, executando um serviço que, de acordo com a lógica da política de saúde que tentava se impor, seria uma atribuição dos órgãos do governo federal (Fernandes, 1989).

A criação do Departamento Nacional de Saúde Pública, em 1920, rompeu a tensão entre os dois institutos, que durou quase duas décadas, centralizando os serviços sanitários no âmbito do governo federal e incorporando, definitivamente, o Instituto Vacínico ao Instituto de Manguinhos - já denominado, então, Instituto Oswaldo Cruz.

Apesar de os serviços de saúde no Brasil apresentarem-se de forma pouco estruturada, até meados do século XX, observa-se a prevalência da forma mais branda da varíola - minor - em detrimento de sua expressão grave e letal - major. A obrigatoriedade da vacinação e sua conseqüente disseminação arrefeceram a expressão da doença, mantendo-a, porém, em patamares distantes da já propalada erradicação.

\section{Campanhas de Controle e Erradicação da Varíola: CNCV e CEV}

A partir da década de 1940 as preocupações com o controle da varíola, e a possibilidade de erradicação da doença, começam a ser expostas internacionalmente nas reuniões e publicações dos órgãos internacionais de saúde. A Oficina Sanitária Panamericana informou, em meados da referida década, que a grande maioria dos países americanos encontrava-se livre da varíola, constando o Brasil entre os poucos que ainda a apresentavam em seu quadro de morbidade. A OMS manifestou, desde sua criação, a importância da implementação de programas nacionais que vislumbrassem a erradicação nos países onde a varíola ainda estivesse presente. A partir de 1958, a erradicação mundial começou, de fato, a constar das propostas formuladas nas assembléias mundiais da Saúde (Fernandes, 2004, 2005, 2006, 2007; Chagas, 2008).

No Brasil, no entanto, apesar das reformulações dos serviços de saúde, em 1930, com a criação do ministério da Educação e Saúde, e da constituição, em 1941, de 12 Serviços Nacionais, direcionados para doenças e ações específicas, o controle da varíola permanecia disperso. As 
ações voltadas para a doença estavam distribuídas em vários órgãos nacionais e locais relacionados à produção e aplicação da vacina, controle de migrantes, educação e propaganda, inquéritos epidemiológicos e levantamentos bioestatísticos. A divulgação da vacina nos serviços de rotina, em campanhas de vacinação em massa e em lugares específicos, como locais de trabalho, bares, restaurantes, casas e, principalmente, as escolas, se dava com o aporte das ações de educação sanitária, presentes, sobretudo, no Serviço Nacional de Educação Sanitária (SNES). O Serviço Especial de Saúde Pública (Sesp), que teve sua origem num acordo firmado entre Brasil e Estados Unidos, em 1942, também contribuiu, significativamente, para a erradicação da varíola no país, com o desenvolvimento de atividades de educação sanitária e difusão da vacina (Fernandes, Chagas \& Souza, 2010a, 2010b; Chagas, 2008).

Somente a partir da década de 1960 foram organizadas, no Brasil, instituições responsáveis exclusivamente pela varíola - a Campanha Nacional Contra a Varíola (1962) e a Campanha de Erradicação da Varíola (1966). As duas instituições assumiam como base a vacinação e a vigilância epidemiológica para o controle e a erradicação da varíola, respondendo às orientações das organizações mundiais da saúde. A difusão da vacina, tanto a partir de estratégias epidemiológicas, como por intermédio das campanhas de vacinação em massa, promovidas pelos serviços locais (estaduais e municipais) e pelo Sesp, por meio das Unidades de Vigilância Epidemiológica (UVEs), configurou-se como o alicerce da erradicação da varíola. Neste sentido, contribuíram a produção da vacina liofilizada, a incorporação da técnica de multipuntura (com agulha bifurcada) e o uso do injetor ped-o-jet para a vacinação, as medidas de cunho educativo, além da aplicação da lei de obrigatoriedade. O aprimoramento diagnóstico colaborou, também, para o estabelecimento do quadro epidemiológico da doença (Fernandes, 2004, 2005, 2006, 2007; Fernandes, Chagas \& Souza, 2010a, 2010b; Chagas, 2008; Gazêta, 2006).

A Campanha de Erradicação da Varíola foi desestruturada em 1970, quando a meta de erradicação da doença no país, estava praticamente encerrada, sendo parte de suas atividades incorporada a Superintendência de Campanhas de Saúde Pública (Sucam). ${ }^{5}$ A erradicação da varíola viabilizou experiências de controle e erradicação de outras doenças, com a incorporação de parte do conhecimento científico então gerado na produção, conservação e aplicação de vacinas, além das estruturas normativas e de ações locais (Fernandes, 2004, 2005, 2006, 2007; Chagas, 2008). 
Foram criados, como legados dessas ações, o Sistema Nacional de Vigilância Epidemiológica (SNVE), que passou a centralizar as informações sobre as doenças de notificação obrigatória no país, e o Programa Nacional de Imunizações (PNI). O Brasil, diante da experiência acumulada e da capacitação de vários sanitaristas no programa de erradicação da varíola, ocupou, ainda, importante papel no processo de erradicação da doença em outros países da Ásia e da África (Chagas, 2008; Fernandes, 2004; Hochman, 2009).

Como último ato governamental referente ao controle da varíola no país, verifica-se, em 1979, a extinção da exigência de apresentação do certificado de vacinação antivariólica em qualquer dos casos anteriormente presentes na legislação brasileira (Chagas, 2008).

\section{Erradicação e risco}

Após a erradicação da doença, da suspensão da vacinação e do conseqüente, esgotamento da defesa imunológica humana, o laboratório passou a ser o único espaço autorizado cientificamente para o vírus, mudando o foco de discussão sobre a varíola. O conhecimento técnicocientífico gerado permitiu, também, o controle absoluto do vírus e sua preservação fora do organismo humano com sua estrutura genética armazenada virtualmente. O processo de erradicação da varíola viabilizou estudos nos campos da microbiologia e da imunologia, nas técnicas de produção, assim como, também, criou importantes parâmetros para a vigilância epidemiológica de outras doenças transmissíveis (Fernandes, 2004; Chagas, 2008; Gazêta et al., 2005; Verani, 1993).

O risco que esse microrganismo superpotente passou a simbolizar acrescentou às discussões seculares uma importante questão acerca do extermínio ou não do vírus, armazenado com forte esquema de segurança em laboratórios de referência da OMS. Esse tema envolve vários interesses em diferentes fóruns de debate, como segurança bélica mundial, bioética e a própria virologia, que o vem utilizando em estudos sobre doenças virais.

$\mathrm{O}$ ataque terrorista de 11 de setembro de 2001, com a derrubada das duas torres do World Trend Center, em Manhatan, Nova York, trouxe à tona o debate em torno da segurança bélica, quando a varíola e o antrax se tornaram ameaças belicistas que poderiam ser utilizados como 
armas poderosas, sem possibilidade de enfrentamento em curto espaço de tempo.

Se por um lado a erradicação extinguiu um problema - a doença -, por outro fragilizou a população em suas disputas por espaço e poder (físico, social e imunológico), devolvendo ao vírus sua capacidade de ação viral.

\section{"Vacina Antivariólica: ciência, técnica e o poder dos homens"}

As três questões, que compõem o título desta publicação - ciência, técnica e poder -, nortearam a pesquisa inicial e abriram caminho para as investigações que procedemos posteriormente em torno da vacina antivariólica. Na busca da compreensão dessas problemáticas, nos encaminhamos para a análise de questões determinadas no âmbito do processo histórico de institucionalização da vacina no Brasil.

Iniciamos a análise com a criação, em 1811, da Junta Vacínica da Corte, que seria o primeiro órgão governamental com a função de divulgar a prática da vacinação humanizada no país. Em 1846 foi criado o Instituto Vacínico do Império, como resultado da reestruturação da Junta Vacínica, que previa a introdução da vacina animal, o que só ocorreu com a criação do Instituto Vacínico Municipal, em 1894, pelo barão de Pedro Affonso.

Assinalamos como marco relevante para a finalização deste trabalho a reestruturação dos serviços de saúde, em 1920, que incorporou o Instituto Vacínico Municipal ao Instituto Oswaldo Cruz.

Subdividimos o texto apresentado nesta publicação em três capítulos. No primeiro, discutem-se as relações entre ciência, técnica e produção, tendo como referência a descoberta de Jenner e as reflexões de Pasteur sobre a vacina antivariólica. O segundo volta-se para a organização institucional implementada durante o Império com o objetivo de possibilitar a prática da vacinação por intermédio da Junta Vacínica e do Instituto Vacínico do Império, introduzindo as primeiras experiências com a vacinação animal, no Brasil, realizadas na Santa Casa da Misericórdia.

O terceiro capítulo trata da sobrevivência do Instituto Vacínico Municipal em novo contexto institucional, polarizado entre propostas de centralização e descentralização dos poderes públicos para a organização dos serviços de saúde. Destacamos o surgimento do conflito entre o barão 
de Pedro Affonso e Oswaldo Cruz, que representou uma das polêmicas da época em torno da centralização dos serviços de saúde e que contribuiu para os diferentes alinhamentos que redundaram em posições antagônicas assumidas por médicos e políticos.

Essa divergência se estendeu ao longo das duas primeiras décadas do século XX, finalizando com a incorporação do Instituto Vacínico Municipal a Manguinhos, que se transformou em Instituto Vacinogênico Federal por ocasião da reforma dos serviços de saúde, implementada por Carlos Chagas em 1920. Tal reestruturação estava fundamentada em uma proposta centralizadora de cunho nacionalista que deu origem ao Departamento Nacional de Saúde Pública, e simbolizou a derrota da concepção institucional que Pedro Affonso havia instaurado em 1894 e que manteve até então.

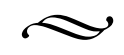

Tentando fugir da retórica dos agradecimentos, porém buscando ser o mais fiel possível aos que contribuíram para a realização deste trabalho, volto-me para os amigos da Casa de Oswaldo Cruz, em particular os do Departamento de Pesquisa. A oportunidade de construirmos juntos uma perspectiva de trabalho traz a estudos como estes, em princípio individuais, uma sensação de trabalho conjunto. Dessa forma, agradeço o carinho intelectual e pessoal com que contribuíram para a conclusão deste estudo.

Ressalto o papel assumido por alguns dos amigos que elegi como leitores críticos deste trabalho em sua versão original, ainda na fase de elaboração da dissertação. A Marli Albuquerque e a Luiz Otavio Ferreira, agradeço as importantes contribuições que me trouxeram ao apontarem questionamentos essenciais na pesquisa. A Nara Britto agradeço a leitura crítica e minuciosa, que proporcionou um retorno de fundamental importância analítica e que só seria possível graças à sua competência acadêmica e à amizade que nos une.

A Maria Amélia Mascarenhas Dantes, que, ao compor a Banca Examinadora que aprovou a dissertação de mestrado, insistiu em que esse esforço fosse levado a um público mais amplo por meio de uma publicação.

Ao grande amigo Paulo Gadelha, que, desde a primeira leitura, ainda em manuscritos, acreditou que o tema era extremamente fértil, propondo-se a orientar a investigação que originou este trabalho, oferecendo, 
inclusive, a estrutura material da Casa de Oswaldo Cruz, da qual era diretor, para sua execução.

A Pedro Paulo Soares e a Carlos Fidelis da Ponte, que, com experiência na organização da exposição "A Revolta da Vacina", me auxiliaram na seleção do material iconográfico, incorporado ao texto para ampliar a possibilidade de interlocução com a temática tratada.

Ao amigo Tarcísio Cunha, que, com sua sensibilidade artística e capacidade técnica, partilhou das primeiras idéias para a formulação da capa da edição original. Destaco ainda o trabalho criterioso e a acolhida sensível da Editora Fiocruz, em particular de Fernanda Veneu e Guilherme Ashton (in memoriam), pela revisão e projeto gráfico na primeira edição. Ao editor executivo da Editora Fiocruz, João Carlos Canossa Mendes, sempre paciente em relação a minhas solicitações como autora, e a Gilberto Hochman - companheiro, amigo, incentivador deste estudo e membro do Conselho Editorial, que sugeriu e encaminhou a proposta da segunda edição desta obra.

A Daiana Crús Chagas, que participou de vários momentos das pesquisas sobre vacina e varíola, desenvolveu importante investigação na linha sobre a erradicação da doença e que se transformou em grande amiga, auxiliando na revisão desta nova edição.

Não poderia deixar de agradecer também a Cláudio Bertolli Filho, que elaborou o texto da contracapa deste livro em sua primeira versão.

A meus pais (in memoriam), pelo carinho e o apoio que sempre demonstraram pela minha opção na vida acadêmica. Agradeço também a minha irmã, Angela Fernandes, pelo auxílio nos momentos finais da obra original, quando o trabalho ainda constituía uma dissertação de mestrado, contribuindo com o companheirismo e a criatividade que lhe são peculiares.

\section{Notas}

1 A autoria da criação da vacina apregoada à Jenner é contestada por Raymond (1982), que a indica como tendo sido criada por Benjamin Jesty. A bibliografia corrente sobre o tema, no entanto, sugere Jenner como o responsável.

2 Sobre a difusão da medicina pasteuriana no Brasil ver, principalmente, Benchimol (1990) e Benchimol e Teixeira, (1994).

3 Barão de Pedro Affonso era médico-cirurgião, atuante no período de final do Império aos primeiros anos do século XX como conselheiro dos assuntos referentes à saúde pública. 
4 O Instituto Soroterápico Federal foi transformado, em 1907, em Instituto de Patologia Experimental, tendo, no ano seguinte, novamente sua denominação alterada para Instituto Oswaldo Cruz. Vários estudos foram formulados sobre a trajetória desse instituto, nos quais se destacam os de Benchimol (1990), Britto (1995) e Fernandes (1989).

5 A Sucam resultou da fusão do Departamento Nacional de Endemias Rurais (DENERu), da Campanha de Erradicação da Malária (CEM) e da Campanha de Erradicação da Varíola (CEV). 